\title{
Parachute tricuspid valve: a systematic review
}

\author{
Shi-Min Yuan* ${ }^{*}$
}

\begin{abstract}
Background: A parachute tricuspid valve is a very rare congenital cardiac anomaly. Its morphological features and clinical implications have not been sufficiently described so far. The purpose of the present systematic review is to disclose the morphological and clinical characteristics of parachute tricuspid valve, and to discuss its diagnostic methods, treatments and patients' outcomes.

Main body: The Preferred Reporting Items for Systematic Reviews and Meta-analyses (PRISMA) statement guidelines were followed in this systematic review. Publications were systematically searched in the PubMed, Highwire Press, and the Cochrane Library databases. By comprehensive retrieval of the pertinent literature published between 1979 and 2019, 13 reports were collected with 14 patients recruited into this study. Their ages ranged from neonate to 52 years old with a median age of 23 years. Tricuspid valve regurgitation of a less-than-severe degree was seen in 6 (60\%) patients, tricuspid valve stenosis was present in $3(30 \%)$ patients and normally functioning tricuspid valve was noted in $1(10 \%)$ patient. All patients had a single papillary muscle in the right ventricle. The chordae tendineae could be normal in length and thickness, or elongated, or shortened and thickened. Forty percent of the patients were asymptomatic or with only mild symptoms and did not need a surgical or interventional therapy, and 6 (60\%) patients were indicated for a surgical/interventional treatment due to their severe presenting symptoms, associated congenital heart defects, and the resultant severe right ventricular inflow obstruction and (or) tricuspid stenosis. Patients' outcomes varied depending on the substantial status of the patients with a survival rate of $70 \%$ and mortality rate of $30 \%$.
\end{abstract}

Conclusion: A few patients with a parachute tricuspid valve are asymptomatic or only with mild symptoms and a surgical or interventional treatment is not required. The surgical/interventional indications for parachute tricuspid valve patients are their severe presenting symptoms, associated congenital heart defects, and the resultant severe right ventricular inflow obstruction and (or) tricuspid stenosis. The survival rate of this patient setting is satisfactory.

Keywords: Cardiac surgical procedures, Congenital heart defect, Parachute tricuspid valve

\section{Introduction}

An atrioventricular valve anomaly caused by a single papillary muscle with unifocal attachment of the chordae tendineae was firstly described by Swan et al. [1] in 1949. This anomaly was termed as "parachute" by Schiebler

*Correspondence: shiminyuan@126.com

Department of Cardiothoracic Surgery, The First Hospital of Putian, Teaching Hospital, Fujian Medical University, 389 Longdejing Street, Chengxiang District, Putian 351100, Fujian Province, China et al. [2] in 1961. Schiebler et al. [2] and El Sayed et al. [3] observed a parachute anomaly affecting the right-sided atrioventricular valve in patients with corrected transposition of the great arteries. The right atrioventricular valve in such patients is actually the morphological mitral valve, whereas the left-sided atrioventricular valve is the tricuspid valve. Thus it should be categorized as parachute mitral valve. Parachute tricuspid valve (PTV) is a very rare congenital lesion. Due to its rarity, the anatomical features and clinical implications of PTVs remain original author(s) and the source, provide a link to the Creative Commons licence, and indicate if changes were made. The images or other third party material in this article are included in the article's Creative Commons licence, unless indicated otherwise in a credit line to the material. If material is not included in the article's Creative Commons licence and your intended use is not permitted by statutory regulation or exceeds the permitted use, you will need to obtain permission directly from the copyright holder. To view a copy of this licence, visit http://creativecommons.org/licenses/by/4.0/. The Creative Commons Public Domain Dedication waiver (http://creativeco mmons.org/publicdomain/zero/1.0/) applies to the data made available in this article, unless otherwise stated in a credit line to the data. 
uncertain. The purpose of this article is to describe the anatomical and clinical features of PTV, and discuss the management, surgical indications and outcomes of the patients.

\section{Materials and methods}

The Preferred Reporting Items for Systematic Reviews and Meta-analyses (PRISMA) statement guidelines were followed in this systematic review. Publications were systematically searched in the PubMed, Highwire Press and the Cochrane Library databases. The period of study was from 1979 to 2019. The MeSH terms and keywords used to identify articles included "parachute tricuspid valve", "supravalvular tricuspid ring", "single papillary muscle", "congenital tricuspid stenosis", "tricuspid valve repair", and "tricuspid valve replacement". The screening of the bibliographic references helped in completing the literature retrieval. Twenty-six articles were found related to the topic and keywords in the literature search; and 13 articles, which met the inclusion criteria during preliminary assessment, were included in this review. The inclusion criteria were publications of any type (clinical research, case series, or case report) on PTV patients at all ages including children (age $<18$ years old) and adults (age $\geq 18$ years old) with substantial patient information for statistical analysis. The exclusion criteria were: parachute mitral valve $(n=7)$, parachute-like tricuspid valve $(n=2)$, parachute-like mitral valve $(n=1)$, parachutelike atrioventricular valve $(n=1)$, accessory tricuspid valve $(n=1)$, and lack of substantial patient information $(n=1)$. A flow chart of literature retrieval was shown in Fig. 1.

The data independently extracted from each study were the study population, demographics, morphology and function of the tricuspid valve, associated congenital heart defects, surgical indications, management and patients' outcomes.

The measurement data were expressed in mean \pm standard deviation. The categorical variables were expressed by frequency and percentage, and were compared by Fisher's exact test. $P<0.05$ was considered statistically significant. An IBM SPSS Statistics version 22.0 was used to perform the statistical analyses.

\section{Results}

In total 13 articles were collected with 14 patients involved [4-16]. Patient information in detail was listed in Table 1. As a result, 12 articles were single case reports and one article was a report inclusive of 2 cases. No clinical research or large case series were included. There were $9(64.3 \%)$ adult and $5(35.7 \%)$ pediatric patients $\left(X^{2}=2.3, P=0.257\right)$. Patient age was not described for one case [12]. For the remaining 13 cases, ages ranged from

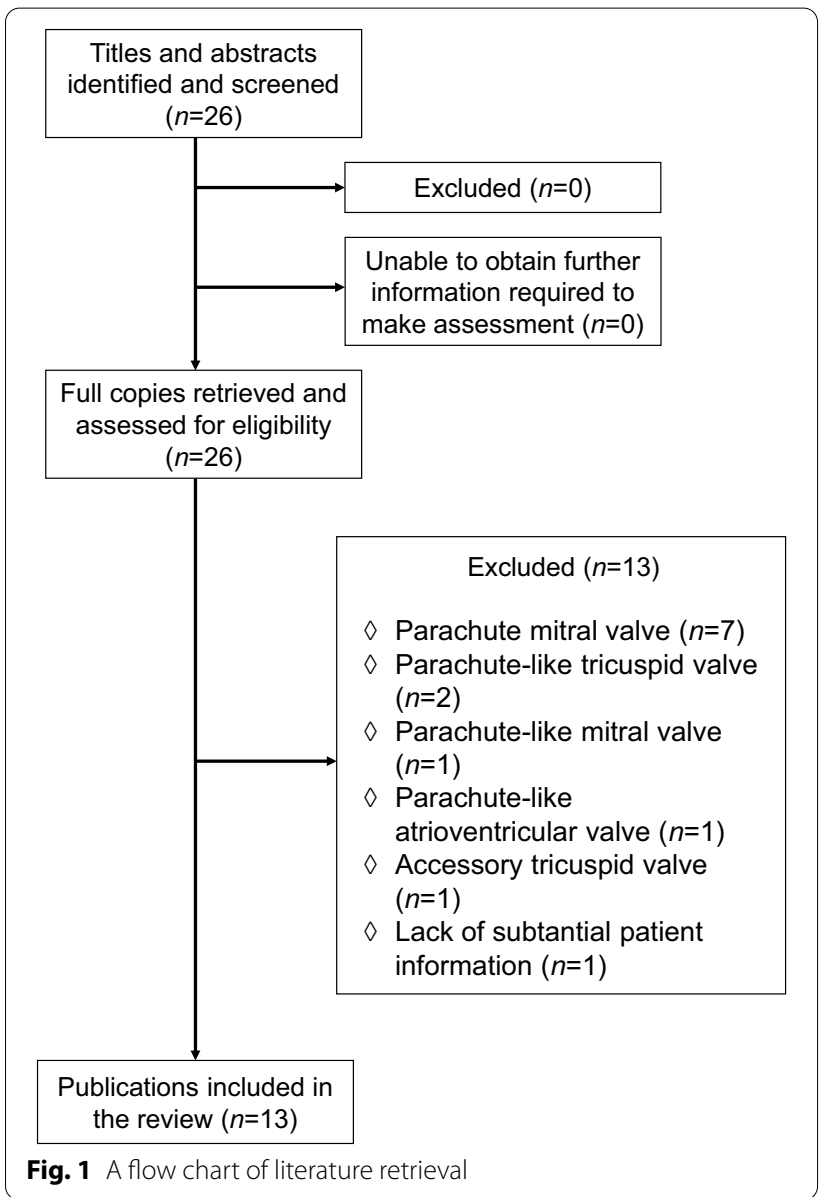

neonate to 52 years old with a median age of 23 years. Their mean age was $21.3 \pm 15.7$ (range, 0-52; median, $23)$ years $(n=13)$. Gender was known for 11 patients: $6(54.5 \%)$ were male and $5(45.5 \%)$ were female patients $\left(\chi^{2}=0.2, P=1.000\right)$.

In one report, patient's symptom was not mentioned [12]. In the remaining 13 patients, 3 (23.1\%) were asymptomatic and $10(76.9 \%)$ were symptomatic $\left(\chi^{2}=7.5\right.$, $P=0.017$ ). The major symptoms of the 10 symptomatic patients were palpitations $[5,7]$, heart failure $[9,10]$, dyspnea [4] and peripheral edema [6].

A cardiac murmur was audible in 11 patients. Actually a systolic murmur was audible in all 11 patients. In 10 patients, the murmur was audible along the sternal border, and in 1 patient, it was heard in the left intercostal space [8]. In one of the patients, an additional diastolic murmur was heard at the apex [4]. A fixed split of the second heart sound was heard in $3(27.3 \%)$ patients [5, $13,14]$.

The electrocardiographical results were described for 7 patients: $2(28.6 \%)$ patients had a normal sinus rhythm [5, 7], and $5(71.4 \%)$ patients had an abnormal 


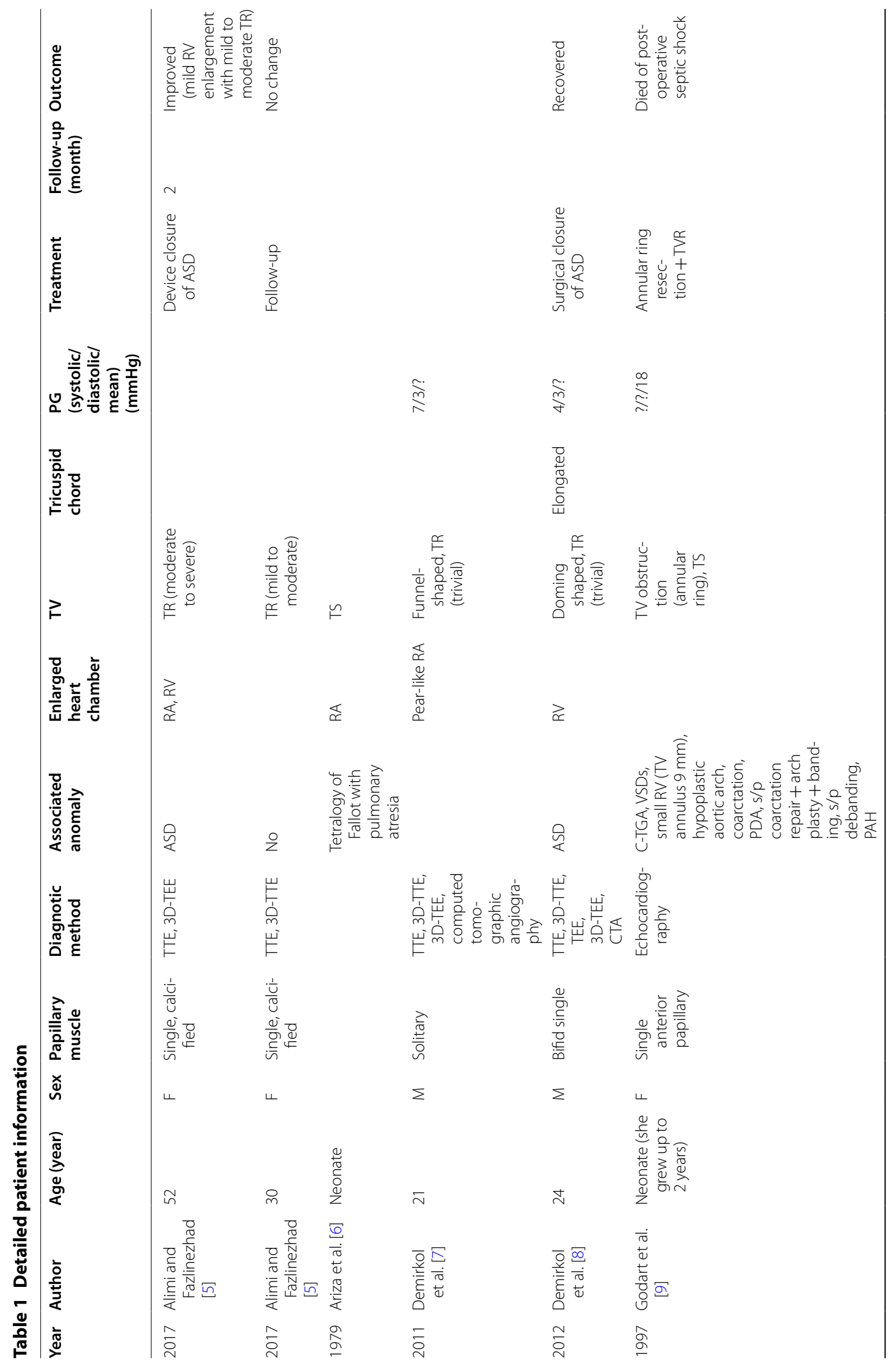




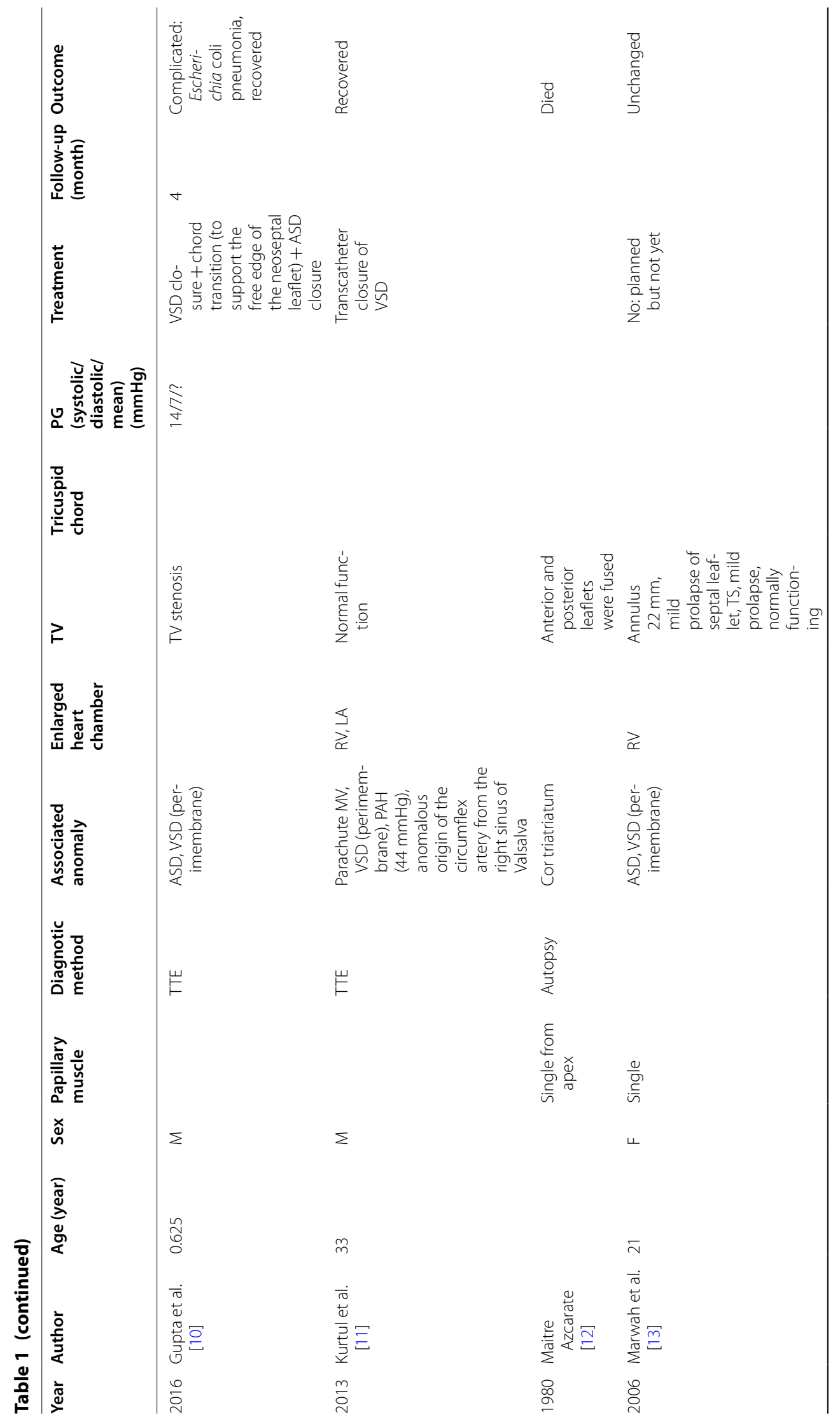




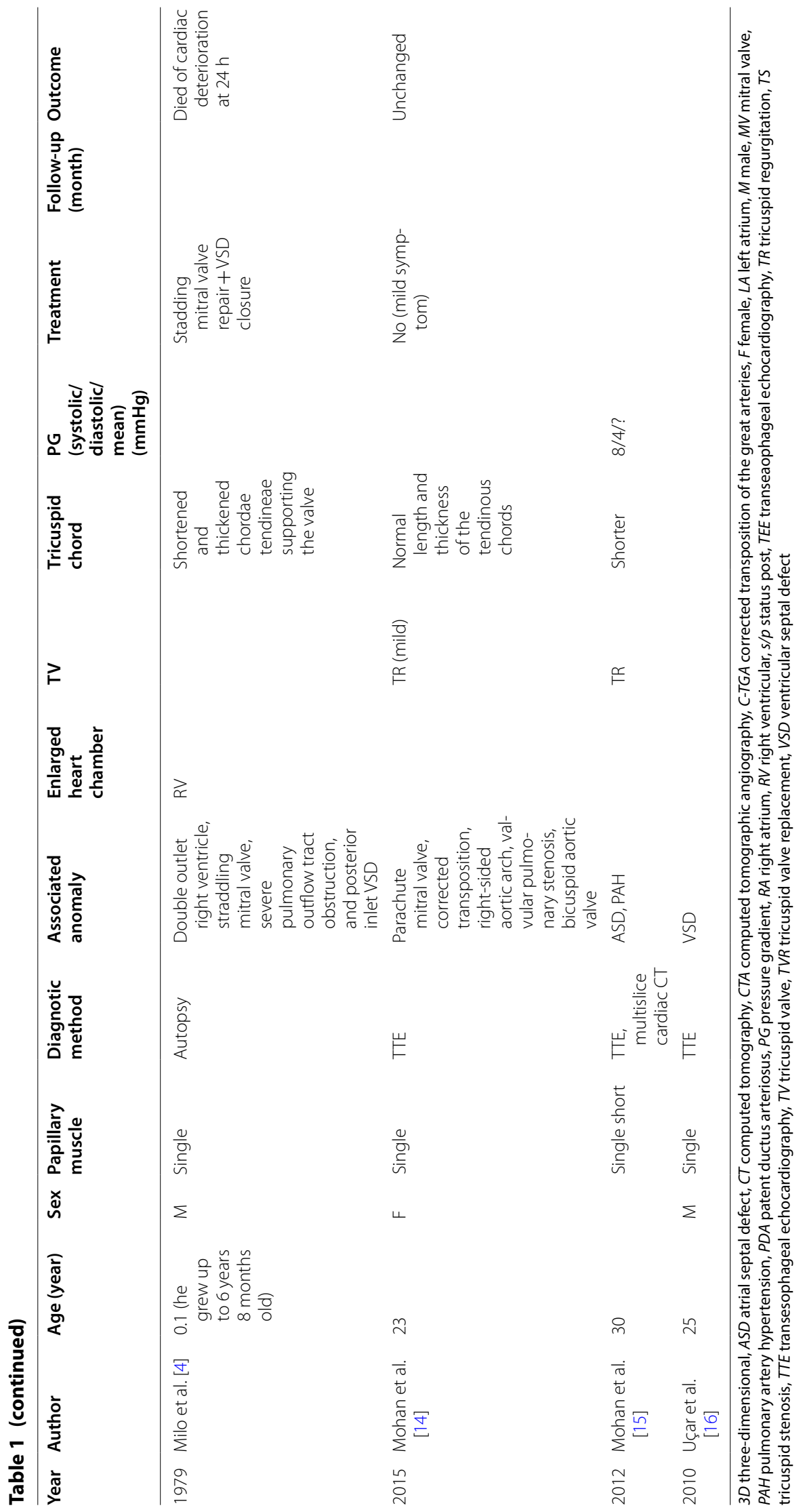


electrocardiogram including right bundle branch block $(n=1)$ [8], conduction defects $(n=1)$ [6], left ventricular hypertrophy $(n=1)$ [9], ST-T changes $(n=1)$ [5], and north-west axis $\left(+150^{\circ}\right)$, right atrial enlargement and prominent $\mathrm{R}$ wave in the $\mathrm{V}_{1}$ lead $(n=1)$ [14].

The diagnostic methods of PTV were described in 12 patients: it was diagnosed by transthoracic echocardiography $(n=5,41.7 \%)[9-11,14,16]$, by both transthoracic and three-dimensional transesophageal echocardiography $(n=2,16.7 \%)$ [5], by transthoracic and transesophageal echocardiography, three-dimensional transthoracic and transesophageal echocardiography and computed tomographic angiography $(n=2,16.7 \%)[7,8]$, by transthoracic echocardiography and multislice cardiac computed tomography $(n=1,8.3 \%)$ [7], and by autopsy $(n=2,16.7 \%)[4,12]$.

In $6(42.9 \%, 6 / 14)$ patients, cardiac chamber enlargement was noted: 4 (66.6\%) patients had one cardiac chamber enlargement (right ventricular enlargement $(n=3)[4,8,13]$ and right atrial enlargement $(n=1)[6])$, and $2(33.3 \%)$ patients had two cardiac chamber enlargement (right atrial and right ventricular enlargement $(n=1)$ [5] and left atrial and right ventricular enlargement $(n=1)[11])$.

All patients had a single papillary muscle in the right ventricle. The papillary muscle was described as: calcified $(n=2)$ [5], short $(n=1)$ [15], from the apex $(n=1)$ [12] and a single anterior one $(n=1)$ [9].

The chordae tendineae were narrated for 4 patients: they were with normal length and thickness $(n=1)$ [14], elongated $(n=1)$ [8], shorter $(n=1)$ [15] and shortened and thickened $(n=1)[4]$.

The morphology and (or) function of the tricuspid valve were described for 12 patients. In one patient, the anterior and posterior leaflets were fused, and the functional status of the tricuspid valve was not given [12]. In another patient, the conditions of one tricuspid valve were confusely narrated as "annulus $22 \mathrm{~mm}$, mild prolapse of the septal leaflet, tricuspid stenosis and functionally normal" [13]. This case was excluded from the statistical analysis of tricuspid valve function. In the remaining 10 patients, $6(60 \%)$ patients had tricuspid regurgitation (it was trivial $(n=2,33.3 \%)[7,8]$, mild $(n=1,16.7 \%)$ [14], mildto-moderate $(n=1,16.7 \%)$ [5] and moderate-to-severe [5] $(n=1,16.7 \%)), 3(30 \%)$ had tricuspid stenosis [6, 9, 10] and $1(10 \%)$ had a normally functioning tricuspid valve [11]. The systolic tricuspid pressure gradient was $8.3 \pm 4.2 \mathrm{mmHg}$ and the mean tricuspid pressure gradient was $4.3 \pm 1.9 \mathrm{mmHg}[7,8,10,15]$.

Of the 14 patients, $12(85.7 \%)$ patients had one or more associated congenital heart defects, including atrial septal defect $[5,8,10,13,15]$, ventricular septal defect $[10,13$, 16], cor triatriatum [12], corrected transposition of the great arteries [9, 14], tetralogy of Fallot and pulmonary atresia [6] and parachute mitral valve and anomalous origin of the circumflex branch from the right sinus of Valsalva [11]; and 2 patients had an isolated PTV (14.3\%). PTVs associated with other cardiac malformations were significantly more than isolated PTVs $\left(x^{2}=14.3\right.$, $P<0.001)$. Moreover, $3(21.4 \%)$ patients had pulmonary artery hypertension $[9,11,15]$.

The treatments were not described for 4 patients. Of the remaining 10 patients, a surgical/interventional treatment was required in $6(60 \%)$ patients: tricuspid valve operation in $2(33.3 \%)$ patients (annular ring resection plus tricuspid valve replacement [9], and chord transition [10]), and surgical/interventional repair of other associated intracardiac anomalies in $5(83.3 \%)$ patients (the patient receiving chord transition had simultaneous atrial and ventricular septal defect closures [10]) including device closure of atrial septal defect $[5,11]$, surgical closure of atrial septal defect [8], chord transition (to support the free edge of the neoseptal leaflet) plus atrial and ventricular septal defect closures [10] and straddling mitral valve repair plus ventricular septal defect closure [4]. In addition, 4 (40\%) patients were on a follow-up only due to mild clinical symptoms. There was no significant difference in the prevalence between surgical/interventional and non-surgical/interventional patients $\left(\chi^{2}=0.8\right.$, $P=0.656$ ).

The surgical/interventional indications for the 6 patients were an associated congenital heart defect $(n=4,66.7 \%)[5,8,11,14]$, congestive heart failure and associated congenital heart defect $(n=1,16.7 \%)$ [10] and tricuspid stenosis and tricuspid annular ring $(n=1$, 16.7\%) [9].

Patients' outcomes were reported for 10 patients: 2 (20\%) patients recovered fully [8, 11], 1 (10\%) patient improved with mild-to-moderate tricuspid regurgitation [5], 1 (10\%) patient was complicated with Escherichia coli pneumonia and finally recovered after treatment [10], $3(30 \%)$ patients remained unchanged [5, 13, 14] and $3(30 \%)$ patients died $[4,9,12]$. The death causes of the 3 deceased patients were postoperative circulatory deterioration [4], postoperative septic shock [9], and an unspecified death cause [12], respectively. The two postoperative deaths occurred in two children at the age of 2 and 6 years 8 months, respectively (Table 2).

\section{Discussion}

In 1979, Milo et al. [4] firstly reported a case of PTV associated with a straddling mitral valve and doubled outlet right ventricle in a baby. He was performed an operation at the age of 6 years 8 months but died soon after the operation. PTV is a very rare congenital cardiac anomaly. It is considered to have been underestimated, as the 
Table 2 Surgical/interventional treatments and prognosis of patients with parachute tricuspid valve

\begin{tabular}{lllll}
\hline Treatment & Treatment technique & Case number & $\begin{array}{l}\text { Patient age } \\
\text { at operation (year) }\end{array}$ & Prognosis \\
\hline Intervention & Transcatheter closure of ASD [5] & 1 & 52 & Improved \\
& Transcatheter closure of VSD [1 1] & 1 & 33 & Recovered \\
Surgery & Surgical closure of ASD [8] & 1 & 24 & $\begin{array}{c}\text { Recovered } \\
\text { Complicated: Escherichia coli pneu- } \\
\end{array}$ \\
& VSD closure + chord transition (to support the free & 1 & 0.625 & monia, recovered \\
$\quad$ edge of the neoseptal leaflet) + ASD closure [10] & & 2 & Died of postoperative septic shock \\
& Annular ring resection + TVR [9] & 1 & 6.67 & Died of cardiac deterioration at 24 h \\
\hline
\end{tabular}

ASD atrial septal defect, TVR tricuspid valve replacement, VSD ventricular septal defect

anatomical features are often sheltered by the associated congenital anomalies [12]. Its prevalence appears to be significantly lower than that of parachute mitral valve [4].

The anatomical features of the atrioventricular valve caused by two asymmetric papillary muscles are termed as a parachute-like valve [17]. The true type of PTVs should be distinguished from the parachute-like valve. In one report, a case of true PTV was mistaken as a parachute-like one [5]. This case was enrolled into this study as a case of true PTV.

Patients with a PTV can be asymptomatic if the valve function is normal or only with mild valve dysfunction [16]. However, in some patients, PTVs may cause tricuspid stenosis and (or) regurgitation. Patients with severe tricuspid stenosis may present with congestive heart failure [10].

A PTV can be visualized in two- and three-dimensional transthoracic and transesophageal echocardiography. A transgastric view is preferred to reveal the features of a PTV, including a solitary papillary muscle, pear-like right atrium and chordal redundancy. Multidetector computed tomography can also reveal the feature of a PTV with a single papillary muscle as well as its attachment site [8].

It has been reported in the literature that PTV was associated with right heart obstructions, such as tetralogy of Fallot [6] and double outlet right ventricle [4]. Atrial and (or) ventricular septal defects were often present in PTV patients. Parachute deformity of both mitral and tricuspid valves were reported in 2 patients $[11,14]$. Mohan et al. [14] summarized 7 cases of PTV patients from the literature, and found the ratio of complex and solitory PVT was 4:3 (1.3:1). Tricuspid stenosis was less significant in PTV patients [5]. Transthoracic/ transesophageal echocardiography was a usual diagnostic technique confirming the morphological features of PTV including single papillary muscle, doming shaped chords and pear-shaped right atrium [7]. Three-dimensional transesophageal echocardiography and computed tomography angiography also confirmed the features of
PTVs [7]. Patients with a PTV often underwent a surgical treatment of the associated cardiac defects, and an operation for the tricuspid valve per se was usually not demanding unless there was severe tricuspid stenosis. Gupta et al. [10] reported their complex tricuspid valvuloplasty including single papillary muscle mobilization, chord transfer, anteroseptal commissure creation and regional annuloplasty for their PTV patient with a unicuspid tricuspid valve. Moreover, in PTV patients, transcatheter atrial septal defect closure could reduce the severity of tricuspid regurgitation as a result of reduction of tricuspid annular dimension and right ventricular volume overload.

The present study revealed that the morphological changes of the tricuspid valve of PTV patients could be functionally normal (10\%), stenosed $(30 \%)$, or regurgitant $(60 \%)$. In line with what was reported in the literature, due to the small number of tricuspid stenosis cases and the mildly regurgitant tricuspid valve, the demanding of tricuspid valve operation was less likely in this patient setting. The tricuspid chords in patients with a PTV varied morphologically significantly from normal to shortened or elongated. In the present study, PTV associated with other cardiac anomalies was seen in $85.7 \%$ of the patients, while isolated PTV accounted for $14.3 \%$ with a ratio of 6:1, significantly exceeding the value reported in the literature. Surgical treatment was performed in $60 \%$ patients with a tricuspid valve operation in one-third and repair of associated cardiac defects in two-thirds of the patients. In $40 \%$ patients, only follow-up is advised due to no or mild symptoms. The prognoses of the patients were good with a survival rate of $70 \%$.

As it was evidenced by the present study, when PTV patients became symptomatic, associated with additional congenital heart defects, or right ventricular inflow obstruction and (or) severe tricuspid stenosis, they were indicated for a surgical/interventional treatment [16]. Patients' outcomes vary from case to case depending on the substantial status of the patients [8]. The present 
article proved that $60 \%$ of patients warranted a surgical/ interventional treatment, and the mortality rate was $30 \%$.

The study materials were based on some case reports, and this situation might bring about possible publication biases at an outcome level, and which was considered a major drawback of the study. In spite of the limitations, the value of the work still exists.

\section{Conclusion}

PTV is a very rare congenital cardiac anomaly. Minority of patients are asymptomatic or only with mild symptoms and do not need a surgical/interventional therapy. The surgical/interventional indications for PTV patients are their severe presenting symptoms, associated congenital heart defects, and the resultant severe right ventricular inflow obstruction and (or) tricuspid stenosis. Patients' outcomes vary depending on the substantial status of the patients.

\section{Acknowledgements}

Not applicable.

\section{Authors' contributions}

SMY: Substantial contribution to the conception and design of the work; and the acquisition, analysis, and interpretation of data for the work; drafting the work and revising it critically for important intellectual content; final approval of the version to be published; agreement to be accountable for all aspects of the work in ensuring that questions related to the accuracy and integrity of any part of the work are appropriately investigated and resolved. The author read and approved the final manuscript.

\section{Funding}

No funding.

\section{Availability of data and materials}

Not applicable.

\section{Ethics approval and consent to participate}

Not applicable.

\section{Consent for publication}

Not applicable.

\section{Competing interests}

The author declares that he has no competing interests.

Received: 13 July 2020 Accepted: 25 September 2020

Published online: 28 October 2020

\section{References}

1. Swan H, Trapnell JM, Dens TJ. Congenital mitral stenosis and systemic right ventricle with associated pulmonary vascular changes frustrating surgical repair of patent ductus arteriosus and coarctation of the aorta. Am Heart J. 1949;38(6):914-23.

2. Schiebler GL, Edwards JE, Burchell HB, Dushane JW, Ongley PA, Wood $\mathrm{EH}$. Congenital corrected transposition of the great vessels: a study of 33 cases. Pediatrics. 1961;27(5):849-88.

3. El Sayed H, Cleland WP, Bentall HH, Melrose DG, Bishop MB, Morgan J, et al. Corrected transposition of the great arterial trunks: surgical treatment of the associated defects. J Thorac Cardiovasc Surg. 1962:44(4):443-58.

4. Milo S, Stark J, Macartney FJ, Anderson RH. Parachute deformity of the tricuspid valve. Thorax. 1979;34(4):543-6.

5. Alimi H, Fazlinezhad A. Two cases of parachute tricuspid valve confirmed by three-dimensional echocardiography. ARYA Atheroscler. 2017;13(2):88-90.

6. Ariza S, Cintado C, Castillo JA, Descalzo A, Cañadas M, Santos J, et al. Parachute tricuspid valve associated with Fallot's tetralogy. Arch Mal Coeur Vaiss. 1979;72(3):317-20.

7. Demirkol S, Gokoglan Y, Battal B, Balta S, Kucuk U. Isolated parachute tricuspid valve in an asymptomatic adult patient detected by three-dimensional echocardiography. Eur Heart J Cardiovasc Imaging. 2012:13(5):444.

8. Demirkol S, Balta S, Unlu M, Bozlar U, Arslan Z, Karaman B. Parachute tricuspid valve in a patient with atrial septal defect detected by two- and three-dimensional echocardiography. Echocardiography. 2012;29(10):E255-E257257.

9. Godart F, Dominique P, Christian R. Parachute tricuspid valve, supravalvar tricuspid ring, and coarctation of aorta in congenitally corrected transposition. Cardiol Young. 1997:7(3):337-9.

10. Gupta A, Kalra R, Joshi RK, Aggarwal N, Aggarwal M, Pandey R, et al. Parachute tricuspid valve: a case treated by open heart surgery. Ann Thorac Surg. 2016;102(5):e443-e44545.

11. Kurtul A, Duran M, Akkaya E, Ornek E. Parachute mitral and tricuspid valves together with ventricular septal defect. Turk Kardiyol Dern Ars. 2013;41(3):264

12. Maitre Azcarate MJ. Parachute deformity of the tricuspid valve. Thorax. 1980;35(3):240.

13. Marwah A, Suresh PV, Shah S, Misri A, Maheshwari S. Parachute tricuspid valve. Eur J Echocardiogr. 2006;7(3):226-7.

14. Mohan JC, Shukla M, Sethi A. Parachute deformity of both atrioventricular valves with congenitally corrected transposition in an adult. Indian Heart 2015:67(6):565-9.

15. Mohan JC, Shekhar C, Mohan V, Kaur B, Singh SK. Parachute tricuspid valve in an asymptomatic adult. Indian Heart J. 2012;64(1):93-4.

16. Uçar O, Ciçekçioğlu H, Vural M, Kocaoğlu I, Aydoğdu S. Parachute tricuspid valve. Anadolu Kardiyol Derg. 2010;10(2):E6-7.

17. Sadeghpour A, Alizadehas A. Parachute deformity of tricuspid valve. In: Sadeghpour A, Kyavar M, Alizadehasl A, editors. Comprehensive approach to adult congenital heart disease. London: Springer; 2014. p. 327-328. https://doi.org/10.1007/978-1-4471-6383-1_47

\section{Publisher's Note}

Springer Nature remains neutral with regard to jurisdictional claims in published maps and institutional affiliations.

Ready to submit your research? Choose BMC and benefit from:

- fast, convenient online submission

- thorough peer review by experienced researchers in your field

- rapid publication on acceptance

- support for research data, including large and complex data types

- gold Open Access which fosters wider collaboration and increased citations

- maximum visibility for your research: over 100M website views per year

At $\mathrm{BMC}$, research is always in progress.

Learn more biomedcentral.com/submissions 